\title{
Rancang bangun mesin press baglog untuk pembuatan media tanam bibit jamur merang
}

\author{
Deri Teguh Santoso $^{1)^{\star}}$, Ratna Dewi Anjani' ${ }^{2)}$, Rianita Puspa Sari ${ }^{3)}$, Febri Aljabar ${ }^{4)}$ \\ ${ }^{1,4)}$ Prodi S1 Teknik Mesin Universitas Singaperbangsa Karawang, Jawa Barat \\ ${ }^{2}$ Prodi D3 Teknik Mesin Universitas Singaperbangsa Karawang, Jawa Barat \\ ${ }^{3)}$ Prodi S1 Teknik Industri Universitas Singaperbangsa Karawang, Jawa Barat
}

Naskah diterima 04/10/2020; direvisi 15/07/2021; disetujui 30/08/2021

doi: https://doi.org/10.24843/JEM.2021.v14.i01.p03

\begin{abstract}
Abstrak
Mesin baglog jamur digunakan untuk membantu petani jamur merang dalam produksi media tanam bibit jamur merang, dengan prinsip kerja berupa penekanan media baglog sehingga menjadi padat sesuai dan pencacahan untuk jerami sebagai bahan untuk media tanam. Untuk bibit jamur merang dikemas dalam kantong (bag) yang berbentuk gelondongan (logs) yang dipadatkan sehingga media tanam jamur sering disebut dengan baglog. Pemadatan media tanam bibit jamur merang bertujuan untuk memperoleh volume media yang lebih padat dan menambah kemampuan menyerap air. Metode perancangan mesin press baglog jamur dengan daya kecil yang sesuai untuk kebutuhan petani kecil. Dalam membuat mesin press baglog jamur perlu dirancang beberapa elemen mesin yang sesuai dengan spesifikasi motor listrik, sabuk, pulley, rantai, sprocket, poros, dan juga kemudahan pengoperasiannya. Hasil perhitungan yang digunakan yaitu daya 0,5 Hp, putaran $1420 \mathrm{rpm}$, perbandingan transmisi 1:60. Nilai tegangan geser pada poros bertangga poros pada punch menghasilkan nilai baik, dapat dilihat dari tegangan rencana lebih tinggi dibandingkan tegangan yang aktual.
\end{abstract}

Kata kunci: Mesin Baglog, Jamur Merang, Tegangan, Pemadatan

\begin{abstract}
Mushroom baglog machine is used to assist mushroom farmers in producing mushroom seedling media. It works by compressing baglog media to make it tightly packed and slicing straw for planting media. Because mushroom seeds are bundled in bags (bags) in the shape of compressed logs, the mushroom growth media is sometimes called baglog. Compaction of mushroom seedling medium seeks to enhance the density of the media and its capacity to absorb water. The approach of building a mushroom baglog press machine with low power consumption is appropriate for small farmers' demands. To build a mushroom baglog press machine, numerous machine parts must be designed according to the requirements of the electric motor, belt, pulley, chain, sprocket, and shaft, as well as the convenience of operation. The calculations assume a power output of $0.5 \mathrm{hp}$, a rotational speed of $1420 \mathrm{rpm}$, and a transmission ratio of $1: 60$. The shear stress value on the step shaft in the punch is an accurate measurement, indicating that the design stress is greater than the actual stress.
\end{abstract}

Keywords: Baglog Machine, Straw Mushrooms, Stress, Press

\section{Pendahuluan}

Jamur merupakan salah satu komoditas pertanian dengan masa depan cerah. Hingga saat ini semakin banyak masyarakat yang mengetahui nilai gizi dari jamur merang dan manfaatnya bagi kesehatan manusia, sehingga kebutuhan akan jamur merang terus meningkat, di sisi lain produksi jamur merang di Indonesia masih rendah, sangat terbatas. Oleh karena itu, nilai ekonomi jamur merang meningkat [1], manfaat lain sebagai anti toksin, anti anemia, kanker dan menurunkan tekanan darah [2].

Media tanam jamur merang merupakan bahan yang digunakan sebagai sumber nutrisi dan mineral bagi jamur. Media tumbuh jamur merang yang biasa digunakan untuk membesarkan atau menumbuhkan jamur merang adalah jerami, akan tetapi jamur merang dapat tumbuh dan berkembang pada media yang merupakan limbah sumber selulosa seperti; jerami, ampas tebu, limbah penggilingan padi, limbah kertas, bahan organik, dll [3].

Perancangan mesin yang dilakukan harus sesuai dengan karakteristik mesin dan tujuan yang akan dicapai, jika salah merencanakan akan berakibat pada faktor lainnya, misalnya semakin tinggi konsumsi energi pada suatu mesin maka berakibat semakin tinggi pula biaya yang harus dikeluarkan [4], kesalahan perancanan desain dan proses produksi mengakibatkan penambahan biaya untuk pekerjaan perbaikan [5].

\section{Metode Penelitian}

\subsection{Desain Mesin Baglog Jamur Merang}

Mesin baglog jamur merang dirancang dalam suatu desain yang sesuai dengan kebutuhan petani atau pihak yang menggunakan. Secara garis besar dikelompokkan menjadi 14 komponen yang dapat dilihat pada Gambar 1 dan Tabel 1.

Tabel 1. Bagian-bagian komponen mesin baglog

\begin{tabular}{|l|l|l|l|}
\hline 1 & Reducer & 8 & Puli \\
\hline 2 & Motor Listrik & 9 & Sabuk \\
\hline 3 & Hopper & 10 & Penerus Daya \\
\hline 4 & As Punch & 11 & Sprocket \\
\hline 5 & Punch & 12 & Poros \\
\hline 6 & Tabung & 13 & Rantai \\
\hline 7 & Pencacah Jerami & 14 & Roda \\
\hline
\end{tabular}




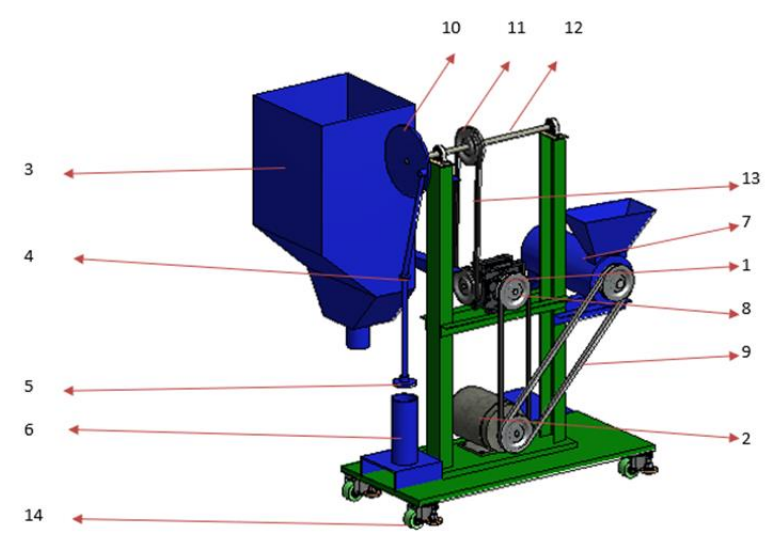

Gambar 1. Mesin baglog jamur merang

2.2. Perhitungan yang digunakan

a. Karakteristik jerami

$\mathrm{T}=\mathrm{F} . \mathrm{r}$

b. Perhitungan daya motor listrik

$P=T \omega$

$P=\frac{T 2 \pi n}{60}$

c. Perhitungan pully dan sabuk $[6,7,8]$

$$
\frac{n_{1}}{n_{2}}=\frac{d_{1}}{d_{n}}
$$

d. Perhitungan rantai dan sprocket $[6,7,8]$

Jumlah gigi pada sprocket: $D$ [inch] = $\frac{\text { pitch }}{\sin \left(\frac{180^{\circ}}{\text { jumlah gigi }}\right)}$

Panjang rantai: $L=2 C+\frac{Z_{2}+Z_{1}}{2}+\frac{\left(Z_{2}-Z_{1}\right)^{2}}{4 \pi^{2} C}$

e. Perhitungan poros $[6,7,8]$

Daya rencana: $\mathrm{Pd}=\mathrm{P}$ fc

Momen puntir: $\mathrm{T}=9,74.10^{5} \frac{P_{d}}{n}$

Tegangan geser yang diizinkan: $\tau_{\mathrm{a}}=\frac{\tau_{\mathrm{b}}}{\mathrm{SF}_{\mathrm{q}} \mathrm{SF}_{2}}$

Diameter rencana: $\mathrm{d}_{\mathrm{s}}=\left[\frac{5,1}{\tau_{\mathrm{a}}} * \mathrm{~K}_{\mathrm{t}} * \mathrm{C}_{\mathrm{b}} * \mathrm{~T}\right]^{1 / 3}$

Tegangan geser yang terjadi: $\mathrm{c}=5,1 \mathrm{~T} /\left(\mathrm{d}_{\mathrm{S}}\right)^{3}$

f. Perhitungan proses pembuatan mesin [8]

1. Proses Pembubutan

Kecepatan potong: $d=\left(d_{0}+d_{m}\right) / 2$

Waktu pemotongan: $t_{c}=\ell_{t} / v_{f}$

Kecepatan makan: $v_{f}=f$. $n$

Kecepatan pemotongan geram: $Z=A$. $v$

2. Proses Drilling

Kecepatan potong: $\mathrm{V}=\frac{\pi d n}{1000}$

Gerak makan per mata potong:

$$
f_{z}=v_{f} /(n z)
$$

Kedalaman potong: $a=d / 2$

Kecepatan penghasilan geram:

3. Proses Cutting

$$
\mathrm{Z}=\frac{\pi d^{2}}{4} \frac{v_{f}}{1000}
$$

Kecepatan potong: $\mathrm{n}=\frac{V c \cdot 1000.60}{\pi \cdot d}$

\section{Hasil dan Pembahasan}

3.1. Karakteristik Jerami

Jika jerami yang digunakan memiliki Panjang ratarata $60 \mathrm{~cm}$ dan massa jerami 70 gram, maka untuk mengetahui daya motor yang dibutuhkan, torsi yang diperlukan yaitu:

$$
\begin{aligned}
& \mathrm{T}=\mathrm{F} \cdot \mathrm{r} \\
& \mathrm{T}=0,6867 \mathrm{~N} \cdot 0,04 \mathrm{~m} \\
& \mathrm{~T}=0,027468 \mathrm{Nm}
\end{aligned}
$$

Jadi nilai torsi dalam satu pisau adalah 0,027468

$\mathrm{Nm}$. Pisau yang digunakan dalam mesin pencacah jerami menggunakan jenis mata pisau berjumlah 15 pisau. Maka nilai torsi dikalikan dengan 15. 0,027468 $\mathrm{Nm}=0,41202 \mathrm{Nm}$.

\subsection{Karakteristik Jerami}

Untuk mengetahui daya motor yang diperlukan dapat dihitung sebagai berikut:

$$
\begin{aligned}
& P=T \omega \\
& P=\frac{T 2 \pi n}{60} \\
& P=\frac{0,412 \mathrm{Nm} \cdot 2 \cdot 3,14 \cdot 1420}{60} \\
& P=61,234 \text { Watt } \\
& 1 \mathrm{Hp}=745,7 \text { Watt } \\
& =\frac{61,234}{745,7} \\
& =0,082 \mathrm{Hp}
\end{aligned}
$$

Jadi daya motor minimal adalah 61,234 Watt atau sama dengan $0,082 \mathrm{Hp}$. Maka motor listrik yang digunakan setidaknya membutuhkan daya sebesar 0.5 $\mathrm{HP}$, jika dengan pendekatan daya motor minimal yang tersedia di pasaran.

\subsection{Perhitungan Puli dan Sabuk}

Pada sistem transmisi yang digunakan dalam mesin baglog jamur ini menggunakan puli dan sabuk sebagai transmisi penggerak komponen yang lainnya. Jika menggunakan puli penggerak dengan ukuran 2 inch, dan puli yang digerakkan ukuran 6 inch, maka hasil putaran terhadap gearbox yaitu:

$$
\begin{aligned}
& \frac{n_{1}}{n_{2}}=\frac{d_{1}}{d_{2}} \\
& n_{2}=\frac{n_{1} d_{1}}{d_{3}} \\
& n_{2}=\frac{1420 \mathrm{rpm} \cdot 2 \mathrm{inch}}{6 \mathrm{inch}} \\
& n_{2}=473,3 \mathrm{rpm}
\end{aligned}
$$

Jadi untuk pully penggerak dengan putaran 1420 rpm dengan ukuran pully 2 inch menghasilkan putaran 473,3 rpm dengan menggunakan puli yang digerakan sebesar 6 inch. Untuk putaran puli ketika terhubung ke gearbox, maka dapat dihitung poros yang digerakan menghasilkan 23,7 rpm.

$$
\frac{n_{1}}{\text { ratio gearbox }}=\frac{1420 \mathrm{rpm}}{60}=23,7 \mathrm{rpm}
$$

\subsection{Perhitungan Rantai dan Sprocket}

Menentukan ukuran sprocket, yang dimaksud dengan ukuran sprocket yaitu diameter pitch-nya. Diameter pitch itu sendiri dihitung sebagai berikut: 


$$
D \text { inch }]=\frac{\text { pitch }}{\sin \left(\frac{180^{\circ}}{\text { jumlah gigi }}\right)}
$$

Jumlah gigi pada sproket $1=18$

$$
D_{1}[\text { inch }]=\frac{0,5 \text { inch }}{\sin \left(\frac{180^{\circ}}{18}\right)}=2,87 \text { inch }
$$

Jumlah gigi pada sproket $2=40$

$$
D_{2}[\text { inch }]=\frac{0,5 \mathrm{inch}}{\sin \left(\frac{180^{\circ}}{40}\right)}=6,37 \mathrm{inch}
$$

Jarak antara pusat sproket (C) berdasarkan pada pedoman perancangan yang diambil berada diantara 30-50 kali pitch, nilai yang diambil adalah 40. Maka, C $=40 \times 0,5$ inch $=20$ inch.

$$
\begin{aligned}
& L=2 C+\frac{Z_{2}+Z_{1}}{2}+\frac{\left(Z_{2}-Z_{1}\right)^{2}}{4 \pi^{2} C} \\
& L=2(20 \text { inch })+\frac{40+18}{2}+\frac{(40-18)^{2}}{4 \pi^{2} .20 \text { inch }} \\
& L=20 \text { inch }+29+\frac{484}{789,5} \\
& L=49,6 \text { pitch }
\end{aligned}
$$

Jadi panjang rantai adalah 49,6 pitch dibulatkan menjadi 50 pitch, atau sama dengan 25 inch.

\subsection{Perhitungan Poros}

Untuk menentukan diameter poros untuk meneruskan daya $0,5 \mathrm{hp}$ pada rpm $1420 \mathrm{rpm}$. Maka perhitungannya sebagai berikut:

- $P d=$ daya rencana $(\mathrm{kW})$

Daya rencana didapatkan dari rumus berikut:

$\mathrm{Pd}=\mathrm{P}$ fc

$\mathrm{Pd}=372,82 \mathrm{w} \cdot 1,8$

$\mathrm{Pd}=671,4 \mathrm{w}$

$\mathrm{Pd}=671,076 \mathrm{~kW}$

Jadi daya rencana yang didapatkan adalah $671,076 \mathrm{~kW}$

- Menghitung $T=$ momen puntir rencana (kg.mm) Momen rencana didapatkan dari rumus berikut:

$T=9,74.10^{5} \frac{P_{d}}{n}$

$\mathrm{T}=9,74.10^{5} \frac{\underset{671,076 \mathrm{~kW}}{1420 \mathrm{rpm}}}{1}$

$\mathrm{T}=460301,4 \mathrm{~kg} \cdot \mathrm{mm}$

Jadi momen rencana yang didapatkan sebesar $\mathrm{T}=460301,4 \mathrm{~kg} \cdot \mathrm{mm}$

- Bahan dan tegangan geser yang diizinkan

Bahan poros yang digunakan adalah baja karbon S45C (JIS 4501) yang mempunyai spesifikasi sebagai berikut:

Kekuatan tarik $\mathrm{T}_{\mathrm{b}}=58 \mathrm{~kg} / \mathrm{mm}^{2}$

$\mathrm{Sf}_{1}=6$ Dipilih karena bahan merupakan jenis $\mathrm{S} 45 \mathrm{C}$

$\mathrm{Sf}_{2}=2$ Dipilih karena dikenakan tumbukan dan kejutan

$\mathrm{K}_{\mathrm{t}}=3,0$ Koreksi untuk momen puntir

$C_{B}=2,3$ Koreksi untuk beban lentur

$\tau_{\mathrm{a}}=\frac{\tau_{\mathrm{b}}}{\mathrm{SF}_{1} \mathrm{SF}_{\mathrm{n}}}$

$\mathrm{T}_{\mathrm{a}}=\frac{58\left(\frac{\mathrm{kg}}{\mathrm{mm}^{2}}\right)}{6.2}$

$\tau_{\mathrm{a}}=4,83 \mathrm{~kg} / \mathrm{mm}^{2}$
Jadi tegangan geser yang diizinkan pada poros sebesar $4,83 \mathrm{~kg} / \mathrm{mm}^{2}$

- Diameter rencana poros $\mathrm{d}_{\mathrm{s}}$

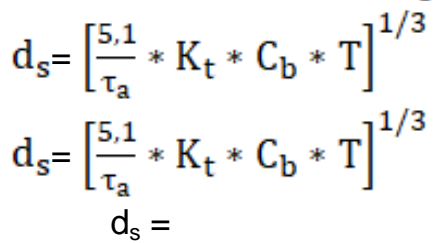

$\left[\frac{5,1}{4,83\left(\frac{\mathrm{kg}}{\mathrm{mm}^{2}}\right)} * 3,0 * 2,3 * 460301,4 \mathrm{~kg} \cdot \mathrm{mm}\right]^{1 / 3}$

$d_{s}=\left[3349,446\left(\mathrm{~mm}^{3}\right)\right]^{1 / 3}$

$\mathrm{d}_{\mathrm{s}}=14,9 \mathrm{~mm}$

Diameter poros nilai yang mendekati 14,9

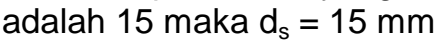

- Konsentrasi tegangan pada poros bertangga adalah:

Parameter 1

r/ds $\quad=2,5 / 15$

$=0,16$

Parameter 2

$\mathrm{D} / \mathrm{ds} \quad=20 / 15$

$$
=1,3
$$

Untuk Mencari Faktor Konsentrasi Tegangan $\beta$.

Nilai yang didapat adalah $\beta=1,25$

- $\mathrm{T}=$ Tegangan geser yang terjadi $\left(\mathrm{kg} / \mathrm{mm}^{2}\right)$

$\tau=5,1 \mathrm{~T} /\left(\mathrm{d}_{\mathrm{s}}\right)^{3}$

$\tau=5,1.459,728 \mathrm{~kg} \cdot \mathrm{mm} /(15 \mathrm{~mm})^{3}$

$\tau=0,69 \mathrm{~kg} / \mathrm{mm}^{2}$

- Perhitungan untuk predikat baik

Kondisi izin

$$
\begin{aligned}
& \frac{\tau_{\mathrm{a}} \cdot \mathrm{sf}_{2}}{\beta}=\frac{4,83\left(\frac{\mathrm{kg}}{\mathrm{mm}^{2}}\right) * 2}{1,25} \\
=7,7 \frac{\mathrm{kg}}{\mathrm{mm}^{2}} &
\end{aligned}
$$

Kondisi yang terjadi

$\mathrm{C}_{\mathrm{b}} \cdot \mathrm{K}_{\mathrm{t} \cdot} \cdot \mathrm{\tau}=2,3 * 3,0 * 0,69\left(\mathrm{~kg} / \mathrm{mm}^{2}\right)$

$=4,7 \mathrm{~kg} / \mathrm{mm}^{2}$

Jadi $\frac{\tau_{\mathrm{a}} * \mathrm{Sf}_{2}}{\beta}>\mathrm{C}_{\mathrm{b}}{ }^{*} \mathrm{~K}_{\mathrm{t}}{ }^{*} \mathrm{~T}$; artinya baik

Sedangkan untuk menentukan poros pada punch ini sama halnya dengan poros pada pencacah jerami, tetapi kecepatan putaran motor listrik yang disalurkan berkurang. Karena melalui gearbox dengan ratio 1:60. Maka putaran motor listrik dibagi dengan ratio gearbox.

$$
\frac{\text { Putaran motor listrik }}{\text { ratio gearbox }}=\frac{1420 \mathrm{rpm}}{60}=23,7 \mathrm{rpm}
$$

Jadi putaran yang diambil adalah $23,7 \mathrm{rpm}$ dibulatkan menjadi $24 \mathrm{rpm}$. Penentuan diameter poros untuk meneruskan daya $0,5 \mathrm{hp}$ pada rpm $24 \mathrm{rpm}$. Maka perhitungannya sebagai berikut.

- $\mathrm{Pd}=$ daya rencana $(\mathrm{kW})$

Daya rencana didapatkan dari rumus berikut: 
$\mathrm{Pd}=\mathrm{P}$ fC

$P d=372,82$ w. 1,8

$\mathrm{Pd}=671,4 \mathrm{w}$

$\mathrm{Pd}=671,076 \mathrm{~kW}$

Jadi daya rencana yang didapatkan adalah $671,076 \mathrm{~kW}$

- Menghitung T = momen puntir rencana (kg.mm) Momen rencana didapatkan dari rumus berikut:

$\mathrm{T}=9,74.10^{5} \frac{P_{d}}{n}$

$\mathrm{T}=9,74.10^{5} \frac{\stackrel{n}{671,076 \mathrm{~kW}}}{24 \mathrm{rpm}}$

$\mathrm{T}=27234501 \mathrm{~kg} \cdot \mathrm{mm}$

Jadi momen rencana yang didapatkan sebesar

$\mathrm{T}=27234501 \mathrm{~kg} \cdot \mathrm{mm}$

- Bahan dan tegangan geser yang diizinkan

Bahan poros yang digunakan adalah baja karbon S45C (JIS 4501) yang mempunyai spesifikasi sebagai berikut:

Kekuatan tarik $\mathrm{T}_{\mathrm{b}}=58 \mathrm{~kg} / \mathrm{mm}^{2}$

$\mathrm{Sf}_{1}=6$ Dipilih karena bahan merupakan jenis S45C

$\mathrm{Sf}_{2}=1,3$ Dipilih karena dikenakan tumbukan dan kejutan

$\mathrm{K}_{\mathrm{t}}=1$ Koreksi untuk momen puntir

$\mathrm{C}_{\mathrm{B}}=1,2$ Koreksi untuk beban lentur

$\tau_{\mathrm{a}}=\frac{\tau_{\mathrm{b}}}{\mathrm{SF}_{\mathrm{q}} \mathrm{SF}_{2}}$

$\mathrm{T}_{\mathrm{a}}=\frac{58\left(\frac{\mathrm{kg}}{\mathrm{mm}^{2}}\right)}{6.1,3}$

$\tau_{\mathrm{a}}=7,4 \mathrm{~kg} / \mathrm{mm}^{2}$

Jadi tegangan geser yang diizinkan pada poros sebesar $4,83 \mathrm{~kg} / \mathrm{mm}^{2}$

- Diameter rencana poros $\mathrm{d}_{\mathrm{s}}$

$$
\begin{aligned}
\mathrm{d}_{\mathrm{s}}= & {\left[\frac{5,1}{\tau_{\mathrm{a}}} * \mathrm{~K}_{\mathrm{t}} * \mathrm{C}_{\mathrm{b}} * \mathrm{~T}\right]^{1 / 3} } \\
\mathrm{~d}_{\mathrm{s}}= & {\left[\frac{5,1}{\tau_{\mathrm{a}}} * \mathrm{~K}_{\mathrm{t}} * \mathrm{C}_{\mathrm{b}} * \mathrm{~T}\right]^{1 / 3} } \\
& {\left[\frac{5,1}{7,4\left(\frac{\mathrm{kg}}{\mathrm{mm}^{2}}\right)} * 1 * 1,2 *\right.}
\end{aligned}
$$

$\left.\mathrm{d}_{\mathrm{s}}=27234501 \mathrm{~kg} \cdot \mathrm{mm}\right]^{1 / 3}$

$\mathrm{d}_{\mathrm{s}}=\left[21749\left(\mathrm{~mm}^{3}\right)\right]^{1 / 3}$

$\mathrm{d}_{\mathrm{s}}=27 \mathrm{~mm}$

Diameter poros nilai yang mendekati 27 adalah

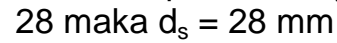

- Konsentrasi tegangan pada poros bertangga adalah:

Parameter 1

$\mathrm{r} / \mathrm{ds}=1 / 28$

$=0,035$

Parameter 2

$\mathrm{D} / \mathrm{ds}=30 / 28$

$=1,07$

Untuk Mencari Faktor Konsentrasi Tegangan $\beta$. Nilai yang didapat adalah $\beta=1,09$

- $\mathrm{T}=$ Tegangan geser yang terjadi $\left(\mathrm{kg} / \mathrm{mm}^{2}\right)$

$$
\begin{aligned}
& \tau=5,1 \mathrm{~T} /\left(\mathrm{d}_{\mathrm{s}}\right)^{3} \\
& \tau=5,1.26298 \mathrm{~kg} \cdot \mathrm{mm} /(28 \mathrm{~mm})^{3} \\
& \tau=6,1 \mathrm{~kg} / \mathrm{mm}^{2}
\end{aligned}
$$

- Perhitungan untuk predikat baik Kondisi izin

$$
\begin{aligned}
\frac{\tau_{\mathrm{a}} \cdot \mathrm{sf}_{2}}{\beta}= & \frac{7,4\left(\frac{\mathrm{kg}}{\mathrm{mm}^{2}}\right) * 1,3}{1,09} \\
& =8,8 \frac{\mathrm{kg}}{\mathrm{mm}^{2}}
\end{aligned}
$$

Kondisi yang terjadi

$$
\begin{aligned}
& \mathrm{C}_{\mathrm{b}} \cdot \mathrm{K}_{\mathrm{t}} \cdot \mathrm{\tau}=1 * 1,2 * 6,1\left(\mathrm{~kg} / \mathrm{mm}^{2}\right) \\
& =7,32 \mathrm{~kg} / \mathrm{mm}^{2} \\
& \text { Jadi } \frac{\tau_{\mathrm{a}} * \mathrm{sf}_{2}}{\beta}>\mathrm{C}_{\mathrm{b}}{ }^{*} \mathrm{~K}_{\mathrm{t}}{ }^{*} \mathrm{~T} \text {; artinya baik }
\end{aligned}
$$

\subsection{Perhitungan Proses Produksi}

a. Proses bubut

Proses pembuatan mesin baglog ini ada bagian yang harus dibubut yaitu poros, karena ada ukuran yang tidak sesuai. Bahan yang digunakan untuk poros adalah baja (JIS G 4501) S45C. Untuk perhitungannya sebagai berikut:

Diketahui:

- Kecepatan potong

Dimana $d=$ diameter rata-rata, yaitu

$\mathrm{d}=\left(\mathrm{d}_{\mathrm{o}}+\mathrm{d}_{\mathrm{m}}\right) / 2$

$\mathrm{d}=(30 \mathrm{~mm}+20 \mathrm{~mm}) / 2$

$\mathrm{d}=25 \mathrm{~mm}$

$\mathrm{V}=\frac{\pi d n}{1000}$

$\mathrm{V}=\frac{3,14.25 .375}{1000}$

$\mathrm{V}=29,4 \mathrm{~mm} / \mathrm{min}$

Maka kecepatan potong yang digunakan yaitu 29,4 $\mathrm{mm} / \mathrm{min}$.

- Kecepatan makan ( $\mathrm{mm} / \mathrm{min})$

$v_{f}=f . n$

$31,25 \mathrm{~mm} / \mathrm{min}=\mathrm{f} .375$

$\mathrm{f}=0,08 \mathrm{~mm}$

Maka gerak makan (feeding) yang digunakan yaitu $0,08 \mathrm{~mm}$

- Kecepatan pemotongan geram

$Z=A . v$

Dimana, penampang geram sebelum terpotong:

$A=f . a$

Jadi

$\mathrm{a}=(\mathrm{do}-\mathrm{dm}) / 2$

$\mathrm{a}=(30 \mathrm{~mm}-25 \mathrm{~mm}) / 2$

$\mathrm{a}=2,5 \mathrm{~mm}$

$Z=$ f.a.v

$Z=0,08 \mathrm{~mm} .2,5 \mathrm{~mm} .29,4 \mathrm{~mm} / \mathrm{min}$

$\mathrm{Z}=5,88 \mathrm{~mm}^{3} / \mathrm{min}$

maka kecepatan menghasilkan/pemotongan geram yaitu sebanyak $5,88 \mathrm{~mm}^{3} / \mathrm{min}$.

b. Proses Drilling

Proses ini diperlukan untuk beberapa part yang harus dilubangi untuk menyatukan part dengan part yang lainnya dengan menggunaka baut dan mur. Untuk perhitungannya sebagai berikut.

- Kecepatan potong 
Diketahui:

$\mathrm{d}=9 \mathrm{~mm}$

$\mathrm{n}=2200 \mathrm{rpm}$

$\mathrm{V}=\frac{\pi d n}{1000}$

$\mathrm{V}=\frac{3,14 \cdot 9 \cdot 2200}{1000}$

$\mathrm{V}=62,172 \mathrm{~mm} / \mathrm{min}$

Maka kecepatan potong yang digunakan yaitu $62,172 \mathrm{~mm} / \mathrm{min}$

- Gerak makan per mata potong

Diketahui:

$\mathrm{V}_{\mathrm{f}}=66$ detik $=1,1$ menit

$\mathrm{z}=2$

$\mathrm{f}_{\mathrm{z}}=\mathrm{v}_{\mathrm{f}} /(\mathrm{nz})$

$\mathrm{f}_{\mathrm{z}}=1,1 \mathrm{menit} /$ (2200rpm.2)

$\mathrm{f}_{\mathrm{z}}=0,00025 \mathrm{~mm} / \mathrm{r}$

Maka Gerak makan per mata potong yaotu 0,00025 mm.r

- Kedalaman potong

$\mathrm{a}=\mathrm{d} / 2$

$\mathrm{a}=9 \mathrm{~mm} / 2$

$\mathrm{a}=4,5 \mathrm{~mm}$

Maka nilai kedalaman potong atau depth of cut yaitu $4,5 \mathrm{~mm}$

- Kecepatan penghasilan geram

$\mathrm{Z}=\frac{\pi d^{2}}{4} \frac{v_{f}}{1000}$

$Z=\frac{3.14\left(9^{2}\right)}{4} \frac{1,1}{1000}$

$Z=0,069 \mathrm{~cm}^{3} / \mathrm{min}$

Maka Nilai kecepatan penghasilan geram yaitu $0,069 \mathrm{~cm} 3 / \mathrm{min}$.

\section{c. Proses Cutting}

Proses ini dilakukan untuk menyesuaikan ukuran dari bahan baku yang didapatkan dengan ukuran yang berlebihan, maka dilakukannya proses ini. Untuk perhitungnannya sebagai berikut.

Menghitung kecepatan potong:

Diketahui:

$\mathrm{n}=11000$

diameter gerinda $=12 \mathrm{~cm}=120 \mathrm{~mm}$

maka

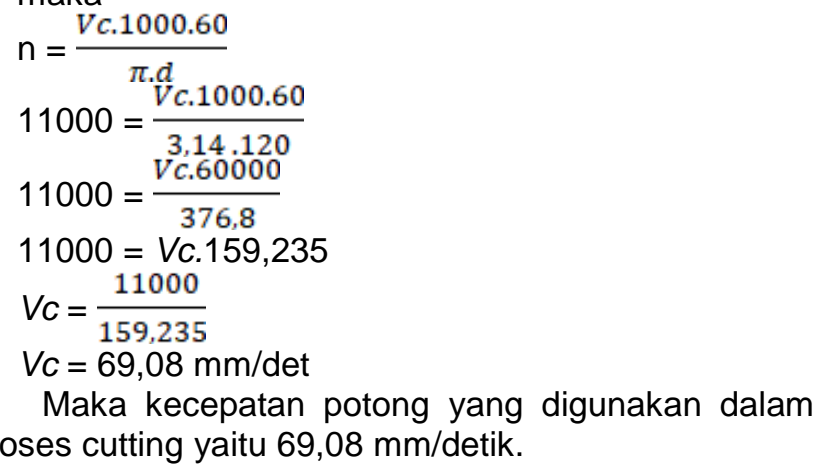

\section{Simpulan}

Proses perancangan haruslah dilakukan dengan sebaiknya, hal ini dikarenakan akan mempengaruhi terhadap hasil yang diperoleh, baik itu kualitas produk maupun biaya yang harus dikeluarkan. Elemen mesin yang direncanakan harus memiliki nilai yang lebih tinggi dibandingkan dengan nilai yang terjadi (aktual). Dalam hal ini yaitu nilai daya rencana terhadap daya yang digunakan, maupun tegangan geser yang direncanakan terhadap tegangan geser yang terjadi. Begitupun pada proses produksi harus direncanakan proses yang terjadi, agar bahan yang digunakan sesuai dengan kapasitas/kemampuan mesin yang digunakan. Sehingga produk yang dihasilkan sesuai mutu dan mesin yang digunakan tetap terjaga kondisi pemesinan yang baik.

\section{Ucapan Terima Kasih}

Ucapan terima kasih disampaikan kepada Kementerian Pendidikan dan Kebudayaan, Riset dan Teknologi atas bantuan dana melalui Program Kemitraan Masyarakat Stimulus (PKMS) Pada Tahun 2019. Juga disampaikan kepada Unverseitas Singaperbangsa Karawang sebagai host penelitian dan pengabdian kepada masyarakat, serta Universitas Udayana yang telah membantu penerbitan artikel ilmiah ini.

\section{Daftar Pustaka}

[1] Sinaga, M. S., Budidaya Jamur Merang, Penebar Swadaya, Jakarta, 2015.

[2] Parjimo, Andoko A., Budidaya Jamur; Jamur Kuping, Jamur Tiram, dan Jamur Merang, Agromedia Pustaka, Jakarta, 2007.

[3] Sinaga, M. S., Jamur Merang dan Budidayanya, Penebar Swadaya, Jakarta, 2000.

[4] Hutagalung, R.P., Ambarita, H., Sitorus, T.B., Nasution, D.M., Ginting, T.U., Pintoro, A. and Napitupulu, F.H., 2016. Analisa Konsumsi dan Biaya Energi pada Mesin Pengering Pakan Ternak Sistem Pompa Kalor Dengan Daya 1 Pk, Jurnal Dinamis, 4(3), pp.9-9, 2016.

[5] Abi Alfiansyah, M., Azevie, U.R., Febryane, Z.E. and Yuwono, B., Rancang Bangun Fixture Pengganti Suteboshi untuk Proses Pemesinan Cam. In Seminar Nasional Teknik Mesin 2021 (Vol. 9, No. 1, pp. 425-433), 2019.

[6] Sonawan, H., Perancangan Elemen Mesin, Alfabeta, Bandung, 2014.

[7] Sularso, Suga, K., Dasar Perencanaan dan Pemilihan Elemen Mesin, Pradya Paramita, Jakarta, 2004.

[8] Taufiq, R., Proses Pemesinan Buku I: Klasifikasi Proses, Gaya dan Daya Pemesinan, Penerbit ITB, Bandung, 2007.

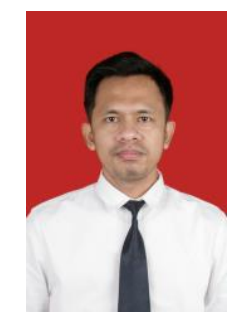

Deri Teguh Santoso menyelesaikan pendidikan terakhir di Institut Teknologi Bandung, pendalaman riset terkait dengan Kelompok Keahlian Teknik Produksi. Saat ini bekerja sebagai dosen di Prodi S1 Teknik Mesin Universitas Singaperbangsa Karawang. Dengan fokus riset terkait dengan pemesinan lanjut dan micro-machining. Kolaborasi dengan peneliti bidang keilmuan lain terkait dengan desain produk, pemberdayaan UMKM dan optimasi produk dan sistem. 